\title{
THE RELATIONSHIP BETWEEN THE ELECTRICAL PROPERTIES OF THICK FILM RESISTORS AND THE THERMAL EXPANSION COEFFICIENT OF THE SUBSTRATES
}

\author{
TOSHIO INOKUMA*, YOSHIAKI TAKETA and MIYOSHI HARADOME ${ }^{\dagger}$
}

\begin{abstract}
The temperature characteristics of $\mathrm{RuO}_{2}$-based thick film resistors on various substrates having different thermal expansion coefficient have been investigated.

It became clear that, if the thermal expansion coefficient of the substrate is larger than that of the thick film resistor. a compression is being exerted by the substrate on the as-fired resistor at low temperature. As temperature rises, the resistance value increases, and the TCR becomes positive.

On the contrary, if the thermal expansion coefficient of the resistor is larger than that of the substrate, the as-fired resistor is being stretched by the substrate at low temperature. As temperature rises, the resistance value decreases, and the TCR becomes negative.
\end{abstract}

\section{INTRODUCTION}

The physical and electrical characteristics of thick film resistors depend largely on the composition of glass which is a component of the resistor, the particle size of the glass and conductive material, and also on the mixture ratio of these two materials ${ }^{1-4}$. The electrical properties also vary with the substrate material adopted and the conditions under which the resistors were manufactured ${ }^{5,6}$. When producing resistors by firing thick film paste, it is therefore necessary to specify minutely the substrate composition and various manufacturing conditions; for example, composition of substrate, firing temperature, firing time, etc. ${ }^{7}$

Recently, $92 \%$ purity alumina, aluminium nitride, silicon carbide and porcenalized steel are also beginning to be applied as thick film circuit substrates ${ }^{7}$.

Table 1 summarizes the relevant mechanical properties of the different substrates that are available. The coefficient of thermal expansion of the glass in the currently used thick films is arranged to be nearly equal to that of $96 \%$ purity alumina ${ }^{8.9}$, and if the thick film paste for the $96 \%$ alumina substrate is used on other substrates mismatching of the coefficient of thermal expansion will influence the physical and electrical properties of the thick film resistors obtained. However, little information is available at present with regard to the influence of this kind of difference in the thermal expansion coefficient on the stress generated between the substrate and resistor or on the electrical characteristics of the resistor, etc.

Under these circumstances, analysis has been made of the stress that is produced in the substrate and $\mathrm{RuO}_{2}$ thick film resistors due to a difference in the coefficient of thermal expansion between the resistor and substrate. We have also examined the influence of different thermal expansion on the electrical characteristics of resistors. We found through experiments that the Temperature Coefficient of Resistance (TCR) increases or decreases depending on whether the difference $\left(\alpha_{\text {sub }}-\alpha_{\text {film }}\right)$ between the coefficient of thermal expansion of the substrate $\left(\alpha_{\text {sub }}\right)$ and that of the thick film resistor $\left(\alpha_{\text {film }}\right)$ is positive or

* Shoei Chemical Inc. 1-1 Nishi-Shinjuku 2-Chome, Shinjuku-ku, Tokyo, Japan

${ }^{\dagger}$ Physical Science Laboratories, Nihon University, 2-1, Izumicho 1-Chome, Narashino-City, Chiba Pref., Japan 
TABLE I

Physical characteristics of various substrates

\begin{tabular}{|c|c|c|c|c|c|}
\hline \multirow[t]{2}{*}{ Material } & \multirow[t]{2}{*}{$\begin{array}{l}\text { Young's Modulus } \\
\left(\times 10^{6} \mathrm{~kg} / \mathrm{cm}^{2}\right)\end{array}$} & \multicolumn{2}{|c|}{$\begin{array}{l}\text { Coefficient of Thermal } \\
\text { Expansion }\left(\times 10^{-7} /{ }^{\circ} \mathrm{C}\right)\end{array}$} & \multicolumn{2}{|c|}{$\begin{array}{l}\text { Calculated Stress } \\
\left(\mathrm{kg} / \mathrm{cm}^{2} /{ }^{\circ} \mathrm{C}\right)\end{array}$} \\
\hline & & $\begin{array}{l}-55 \text { to } \\
+25^{\circ} \mathrm{C}\end{array}$ & $\begin{array}{l}+25 \text { to } \\
+300^{\circ} \mathrm{C}\end{array}$ & $\begin{array}{l}-55 \text { to } \\
+25^{\circ} \mathrm{C}\end{array}$ & $\begin{array}{l}+25 \text { to } \\
+300^{\circ} \mathrm{C}\end{array}$ \\
\hline $18 \mathrm{Cr} \mathrm{Stcel}^{1}$ & 2.0 & - & 120 & - & 3.1 \\
\hline $16 \mathrm{Cr} \mathrm{Stecl}^{1}$ & 2.1 & 88 & 95 & 1.6 & 1.4 \\
\hline Forsterite ${ }^{1}$ & 2.4 & 73 & 86 & 0.6 & 0.9 \\
\hline Stcatite' & 2.5 & 64 & 80 & 0 & 0.5 \\
\hline $96 \%$ Alumina $^{2}$ & 3.5 & 51 & 76 & -0.8 & 0.2 \\
\hline Mullite' & 2.5 & 42 & 53 & -1.4 & -1.3 \\
\hline Si Carbide 2 & 4.6 & - & 41 & - & -1.3 \\
\hline Si Wafer ${ }^{2}$ & - & - & 40 & - & -2.2 \\
\hline Used Glass² & 0.65 & 64 & 73 & & \\
\hline
\end{tabular}

Glass composition; $63 \mathrm{PbO} .25 \mathrm{~B}_{2} \mathrm{O}_{3} .12 \mathrm{SiO}_{2}(\mathrm{wt} \%$ )

${ }^{1}$ From catalogued data ${ }_{2}^{2}$ Measured Value

negative, and hence understood the reason why a minimum value exists in the resistancetemperature characteristic curve.

\section{SPECIMENS}

\subsection{Substrate}

We adopted various substrates having different coefficient of thermal expansion $\alpha_{\text {sub }}$, ranging from $40 \times 10^{-7} /{ }^{\circ} \mathrm{C}$ to $120 \times 10^{-7} /{ }^{\circ} \mathrm{C}$. In order to eliminate the chemical interaction between such substrates and the resistors, and also to eliminate the influence caused by the difference in the surface conditions of the substrates, the substrate surfaces were partially covered with crystallized glass of $20 \mu \mathrm{m}$ thick, as shown in Figure 1, and the thick film resistors were formed on these glass surfaces.

The thickness of the crystallized glass layer formed on the substrate is far smaller than the thickness of the substrate, and the Young's modulus of this glass is 5 to $8 \times 10^{3} \mathrm{~kg} / \mathrm{mm}^{2}$ which is smaller than that of the substrate, i.e., 30 to $40 \times 10^{3} \mathrm{~kg} / \mathrm{mm}^{2}$. This means that the presence of the crystallized glass can be neglected in the experiment.

\subsection{Resistors}

The resistor material used had a mean particle size of $370 \mathrm{~A}$ for the $\mathrm{RuO}_{2}$ particles and a mean size of $1.2 \mu \mathrm{m}$ for the borosilicate glass. The glass had a composition of $63 \mathrm{PbO} .25 \mathrm{~B}_{2} \mathrm{O}_{3} \cdot 12 \mathrm{SiO}_{2}$, softening point of $520 \mathrm{C}$, and $\alpha_{\text {glass }}$ of $71 \times 10^{-7} /{ }^{\circ} \mathrm{C}$. The $\alpha_{\text {film }}$ is nearly the same as that of this borosilicate glass. These two materials were mixed at various $\mathrm{RuO}_{2} /$ glass mixture ratios (wt \%), ranging from 50/50 to 10/90, and the resultant mixture powder was dispersed uniformly in an organic solvent to make the resistor paste. These were then printed on the various substrates using a 250 mesh stainless screen. The substrate with resistor was then fired at $800^{\circ} \mathrm{C}$ for 10 minutes. The dimensions of the specimens were $2 \mathrm{~mm}$ $\times 4 \mathrm{~mm}$, and the thickness was $12 \mu \mathrm{m}$.

\section{RESULTS OF EXPERIMENT}

The resistance-temperature characteristics of the resistors on various types of substrates are shown in Figure 2, and the relationship between the resistance value and TCR are shown in 


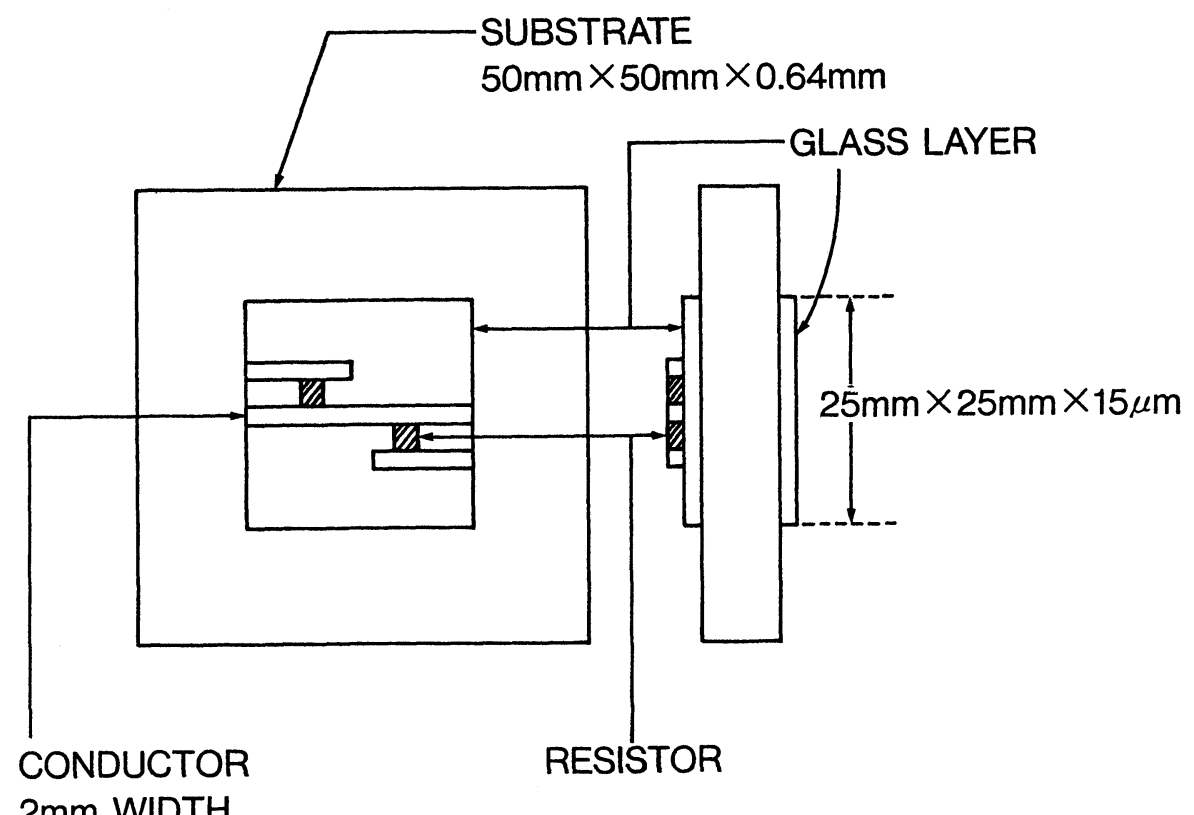

\section{$2 \mathrm{~mm}$ WIDTH}

FIGURE 1 Dimensions and shape of specimens.

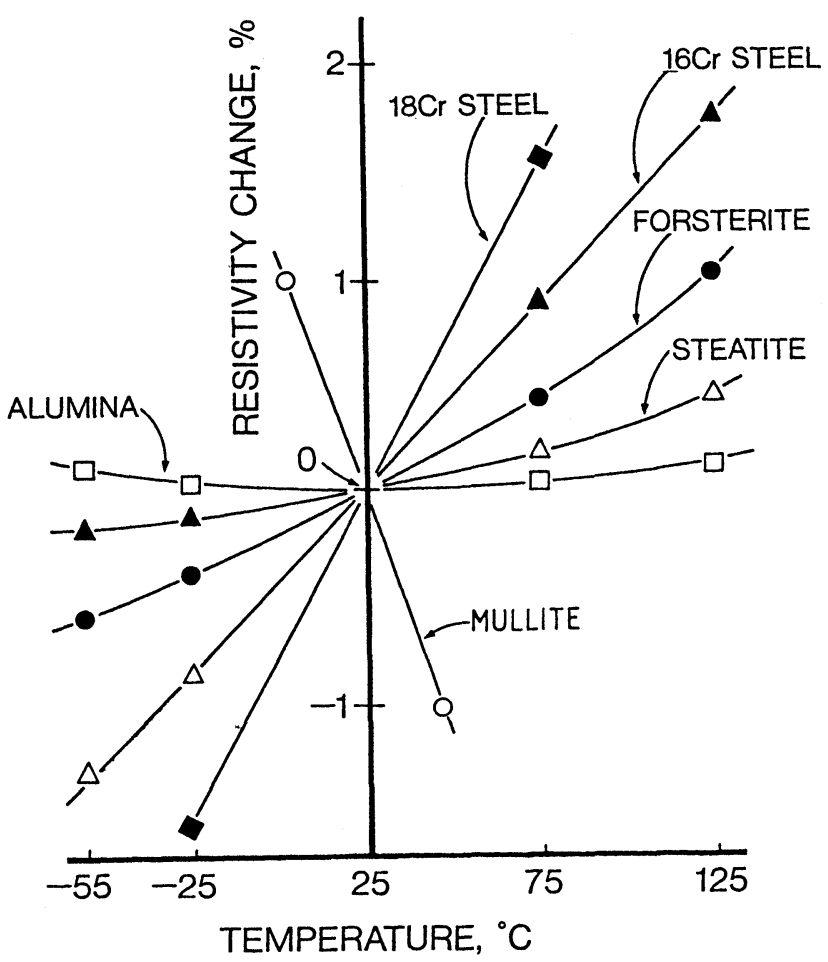

FIGURE 2 Dependence of resistivity of resistors on various substrates on temperature. $\left(\mathrm{RuO}_{2} /\right.$ glass $=23 / 77$, firing temperature $\left.800^{\circ} \mathrm{C}\right)$ 


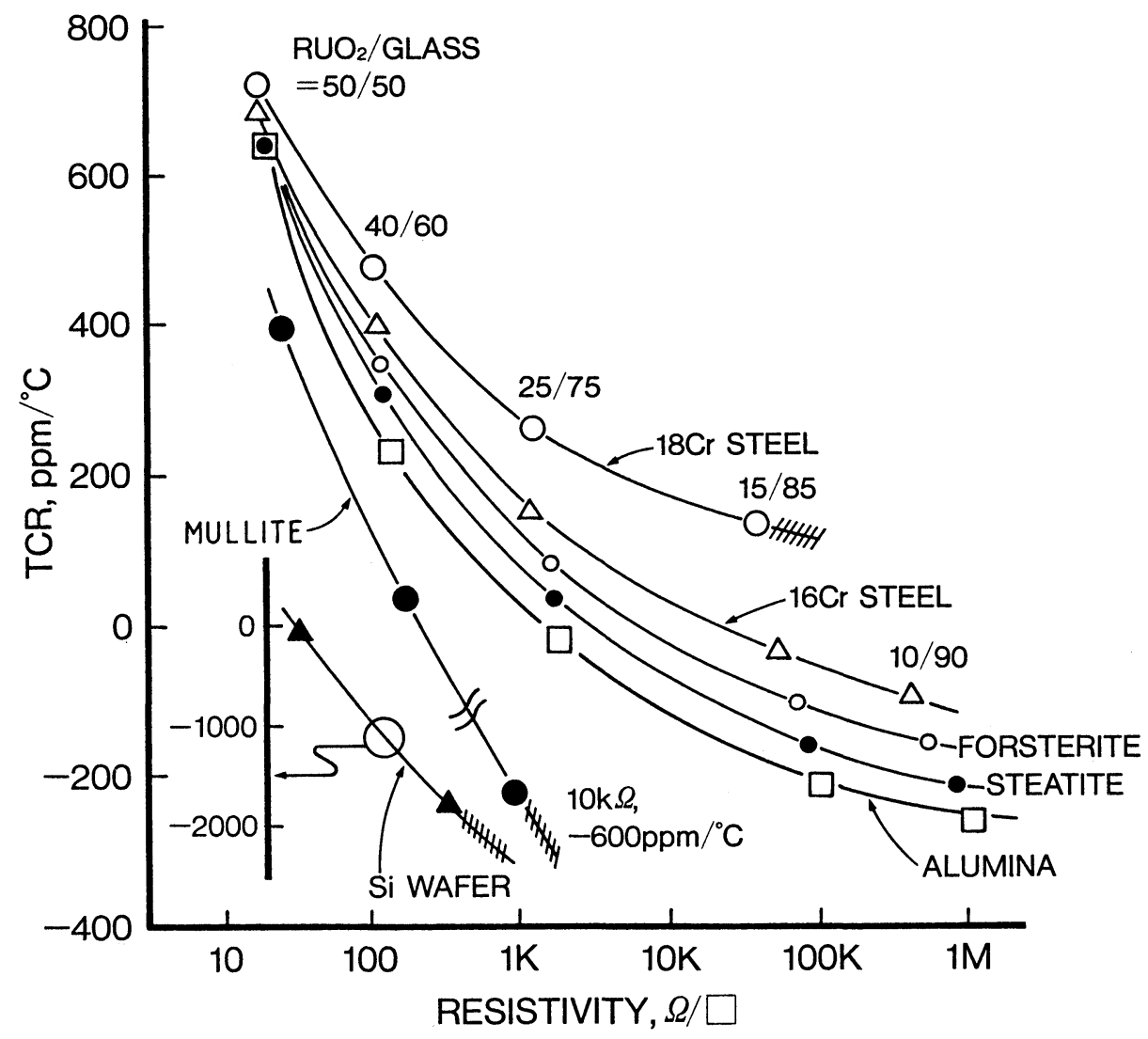

FIGURE 3 Relations between resistivity and TCR of resistors on various substrates. $\left(\mathrm{RuO}_{2} /\right.$ glass $=50 / 50$ to $10 / 90$ firing temperature $\left.800^{\circ} \mathrm{C}\right)$

Figure 3. When the difference in coefficient of thermal expansion is larger between the resistor and substrate, the resistance values become unstable in the high resistance range. The resistors in the hatched areas in Figure 3 showed unstable characteristics.

For the purpose of investigating the phenomina of this unstable resistance region, resistors having three different coefficients of thermal expansion $\left(\alpha_{\text {glass }}\right)$ were prepared on $\mathrm{SiC}$ substrates. These resistors were:- (A) with $\alpha_{\text {glass }}$ of $54 \times 10^{-7} /{ }^{\circ} \mathrm{C}$, which was close to the value of $\mathrm{SiC},(\mathrm{B})$ of $77 \times 10^{-7} /{ }^{\circ} \mathrm{C}$, and $(\mathrm{C})$ of $91 \times 10^{-7} /{ }^{\circ} \mathrm{C}$. These resistors were examined to see how the resistance value varies with temperature in the temperature range from $-50^{\circ} \mathrm{C}$ to $+350^{\circ} \mathrm{C}$.

As shown in Figure 4, the variation range with time of the resistance value of the specimen (A) became smaller as the temperature increased, finally becoming roughly constant at $350^{\circ} \mathrm{C}$. The specimen (B) exhibited at $125^{\circ} \mathrm{C}$ roughly the same characteristics as that of specimen (A) at $-50^{\circ} \mathrm{C}$. The specimen $(\mathrm{C})$ showed similar characteristics when it is heated to $350^{\circ} \mathrm{C}$. The variation range of the resistance value became small as the temperature increased further.

The relationships between the coefficient of thermal expansion of the substrate and TCR are shown in Figure 5. If $\alpha_{\text {sub }}<\alpha_{\text {film }}$, the TCR has a large negative value. On the contrary, the TCR becomes a large positive value as the glass content of the thick film resistor decreases. 


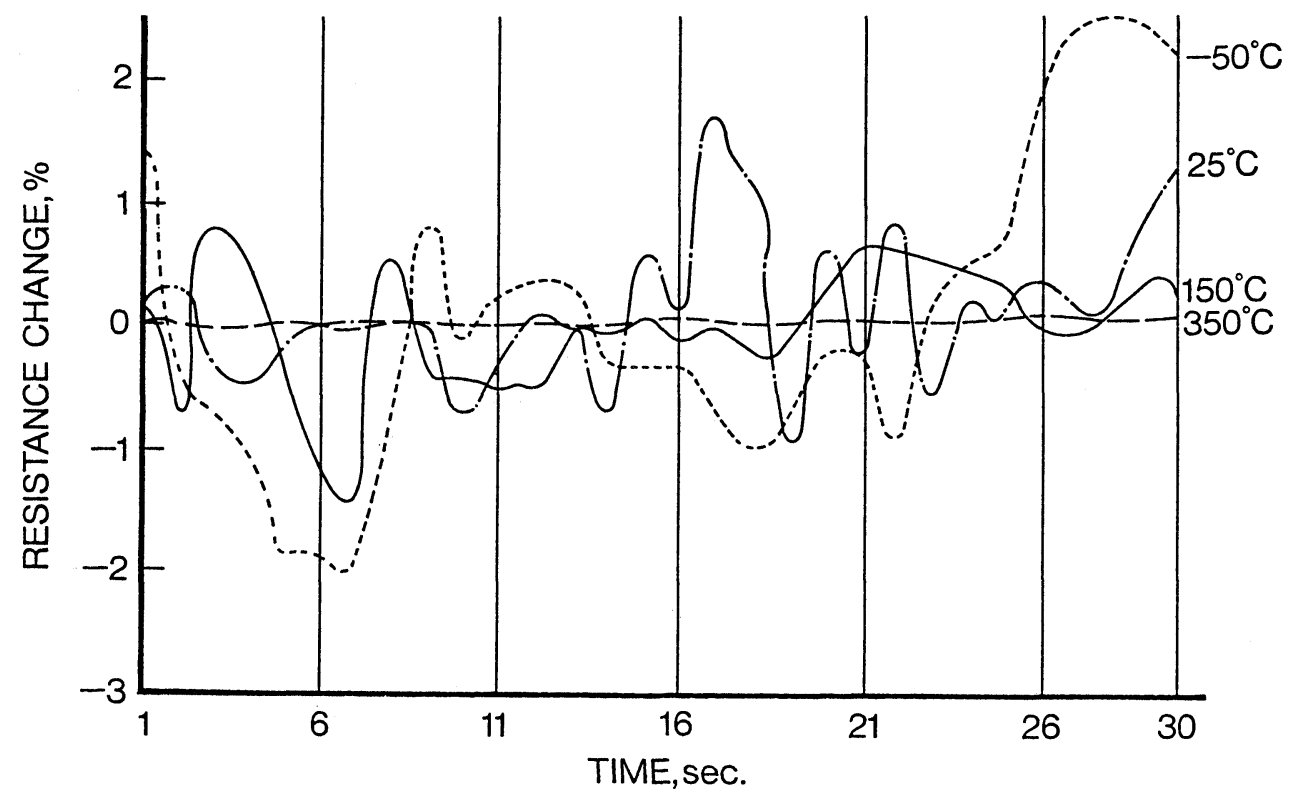

FIGURE 4 Dependence of resistivity of resistors on $\mathrm{SiC}$ substrates on temperature.

$\left(\mathrm{RuO}_{2} /\right.$ glass $=20 / 80$, thermal expansion coefficient of glass $=54 \times 10^{-7} /{ }^{\circ} \mathrm{C}$, firing temperature $\left.800^{\circ} \mathrm{C}\right)$

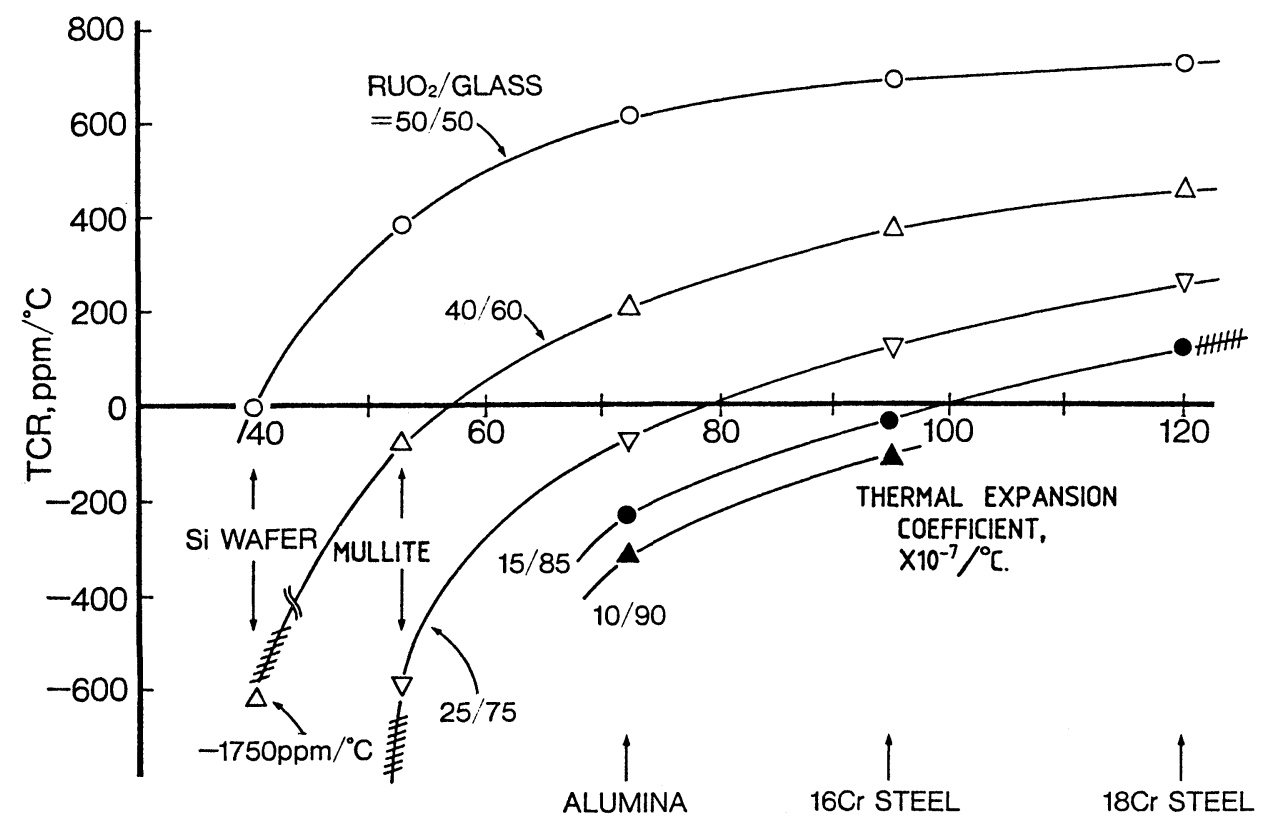

FIGURE 5 Dependence of TCR on thermal expansion coefficient of substrate 


\section{DISCUSSION}

A thick film resistor, the thermal expansion coefficient of which is largely different from that of the substrate, is stressed on cooling after it is fired. The individual conductive particles in the thick film resistor are compacted together by that stress, because these particles are not properly sintered ${ }^{4}$, and thus more electric current paths are formed.

The effect of the difference between $\alpha_{\text {sub }}$ and $\alpha_{\text {film }}$ on the electrical properties of the resistor can be explained by the stress model illustrated in Figure 6 . If $\alpha_{\text {sub }}>\alpha_{\text {film }}$, a compressive stress is exerted on the resistor as shown in Figure 6(a) because shrinkage of the substrate is larger than that of the resistor. On the contrary, if $\alpha_{\text {sub }}<\alpha_{\text {film }}$, the difference in the shrinkage between substrate and resistor puts the resistor into tension, as shown in Figure 6(c). Consequently, the resistivity becomes smaller in the case (1) and larger in the case (2), compared with the resistivity obtained when $\alpha_{\text {sub }}$ is equal to $\alpha_{\text {film }}$.

When the temperature of the resistor under stress rises, the following phenomena will result: If $\alpha_{\text {sub }}>\alpha_{\text {film }}$, tensile stress is exerted on the resistor as shown in Figure 6(b) as temperature increases, and this tensile stress can cancel the compressive stress exerted at room temperature. If $\alpha_{\text {sub }}<\alpha_{\text {film }}$, the substrate and resistor expand differently as the temperature rises, as shown in Figure 6(d), and the resultant compressive stress reduces the resistance value, thereby changing the TCR to a negative value.

The stress $S$ that can affect the resistor in the above-mentioned manner can be approximated by the following equation ${ }^{10}$ with respect to the temperature change, $\Delta \mathrm{T}^{\circ} \mathrm{C}$.

$$
\mathrm{S}=\mathrm{E}_{\text {film }}\left(\alpha_{\text {sub }}-\alpha_{\text {film }}\right) \Delta \mathrm{T}
$$

In this equation, $\mathrm{E}_{\mathrm{film}}$ is the Young's modulus of the resistor. The stress, shown in Table I, is being exerted on the resistor.

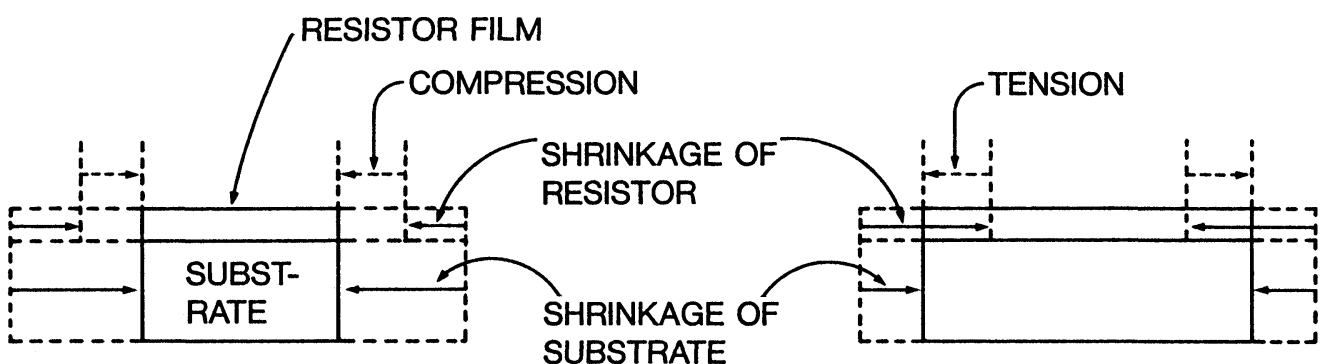

(a)

(C)

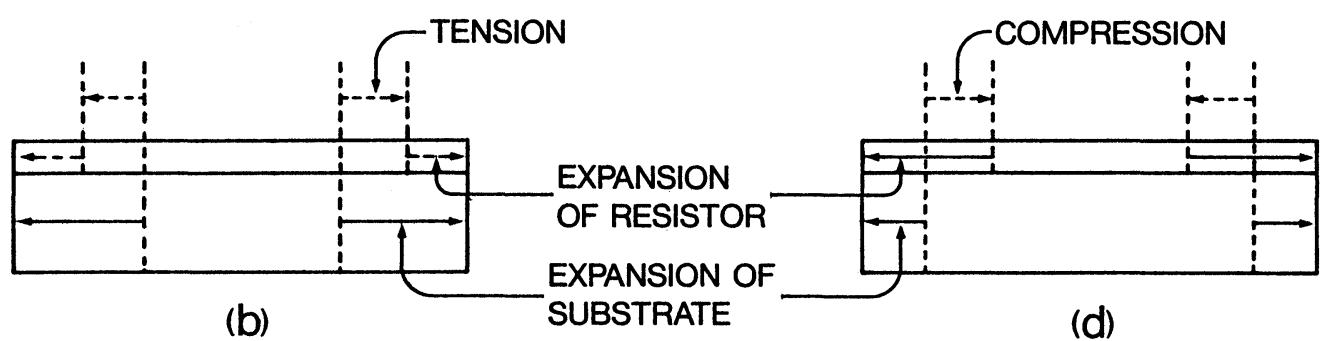

FIGURE 6 Models of strain or stress occurring in thick film resistors and substrates

(a) and (b) $\alpha_{\text {sub }}>\alpha_{\text {film }}$

(c) and (d) $\alpha_{\text {sub }}<\alpha_{\text {film }}$

(a) and (c) at room temperature

(b) and (d) at elevated temperature 
This stress model explains why the resistance value fluctuates at low temperatures while it remains constant and stable in the high temperature range as shown in Figure 4, it also explains why the resistance-temperature characteristic curve shows a positive gradient if $\alpha_{\text {sub }}$ $>\alpha_{\text {film }}$, while it becomes negative in the opposite case (as shown in Figure 2).

It is also possible to explain why the resistance-temperature curve of the $\mathrm{RuO}_{2}$ thick film resistor on the alumina substrate shows a parabolic form. This is because of the relationships of the thermal expansion coefficients between the two substrates are $\alpha_{\mathrm{Al}_{2} \mathrm{O}_{3}}<\alpha_{\text {glass }}\left(\risingdotseq \alpha_{\text {film }}\right)$ at low temperature and $\alpha_{\mathrm{Al}_{2} \mathrm{O}_{3}}>\alpha_{\text {glass }}$ at high temperature (see Table I. Accordingly, when the temperature falls, in the low temperature range, the difference in the shrinkage between the resistor and alumina substrate affects on the resistor as a tensil stress (as shown in Figure 6(c) and Table I). Thus, the resistance value increases.

When the temperature rises, in the high temperature range, the difference in expansion between the resistor and alumina substrate affects the resistor as a tensile stress (as shown in Figure 6(b)), thus making the resistance value increase.

\section{CONCLUSION}

$\mathrm{RuO}_{2}$ thick film resistors were prepared on various types of substrates having different coefficients of thermal expansion, and their temperature characteristics were examined. The results obtained can be summerized as follows:

1) If $\alpha_{\text {sub }}>\alpha_{\text {film }}$, a compressive stress exists in the resistor at room temperature, but a tensile stress begins to appear in resistor as the temperature rises. Thus, the resistance value increases as the temperature rises.

2) If $\alpha_{\text {sub }}<\alpha_{\text {film }}$, the phenomenon is the opposite to that of item 1) above, and the resistance value decreases as the temperature rises.

3) The parabolic form of the resistance-temperature characteristic curve of $\mathrm{RuO}_{2}$ thick film resistors on alumina substrates is caused by a difference in the coefficient of thermal expansion between alumina and resistor in both the low and high temperature regions.

\section{REFERENCES}

1. T.V. Nordstorm and C.R. Hills, "Microstructural Studies of Thick Film Resistors using Transmission Electron Microscopy" in Proc. 1979 Hybrid Microelectronics Symp. pp. 40-45, (1979)

2. R.W. Vest, "Conduction Mechanisms in Thick Film Microstructures" DAHC-15-70-G7 and DAHC-15-73-G8, ARPA order No. 1642, Dec., (1975)

3. C. Schaffer and J. Sergent, "The Effect of Particle Size Distribution on the Electrical Properties of RuO $\mathrm{T}_{2} \mathrm{Thick}$ Film Resistors" in 1977 Proc. Hybrid Microclectronics Symp., pp. 60-64, (1977)

4. T. Inokuma, Y. Taketa and M. Haradome, "Conductive and Insulative Particle Size-effects for the Electrical Properties of $\mathrm{RuO}_{2}$ Thick Film Resistors", IEEE Trans. Components, Hybrid and Manufacturing Technol., CHMT8, No. 3, pp. 372-373, (1985)

"Resistors and the Influence of Glass Particle Size on their Electrical Properties", IEEE Trans. Components, Hybrids and Manufacturing Technol. Vol. CHMT-7, No. 2, pp. 166-175, (1984)

5. A. Cattaneo, L. Pirozzi, B. Marlen and M. Prudenziati, "Influence of the Substrate on the Electrical Properties of Thick Film Resistor", in 1977 Proc. of the European Hybrid Microelectronic Conf., pp. 123-132, (1977)

6. M.V. Coleman, "Screen Printed Conductors and Resistors on Alternative Substrates to Alumina" in 1980 Proc., Hybrid Microelectronics Symp. pp. 104-110, (1980)

7. Nihon Microelectronics Editing, "Thick Film Technology" Tokyo Kogyoshoosa-kai Publishing Co., 1983, Ch. 2., pp. 5-75

8. R.D. Jones, "Hybrid circuit Design and Manufactures”, Marcel Dekker, Inc., New York, Ch. 2, pp. 9-21 (1982)

9. O. Abe and Y. Taketa, "Thick Film Sensors (II)", J. College Industrial Technology, Nohon Univ., No. 16, pp. 87-93, (1984)

10. T. Moritani and H. Tashiro, Editor, "Handbook of Glass', Asakura Shoten, P.509, (1972) 

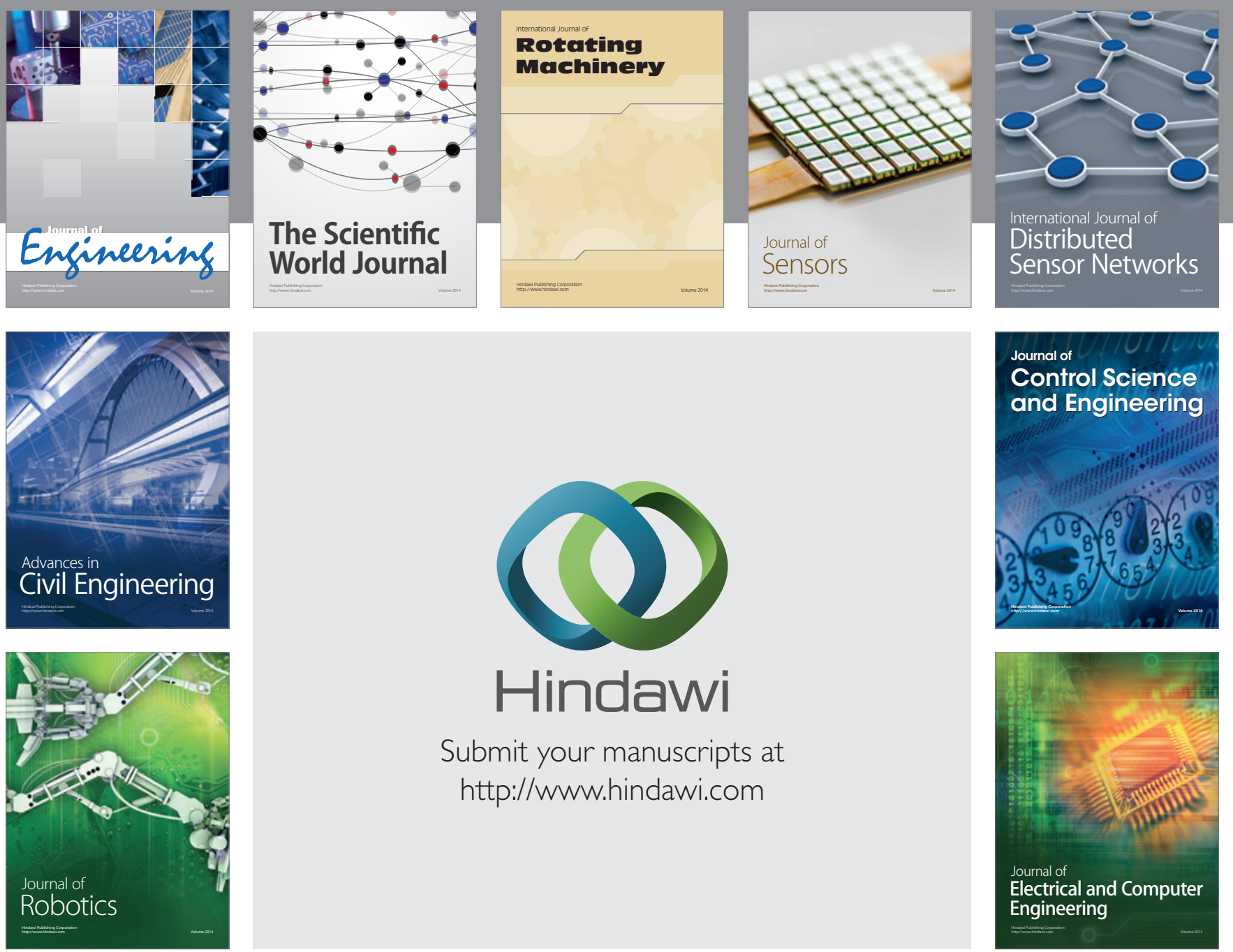

Submit your manuscripts at

http://www.hindawi.com
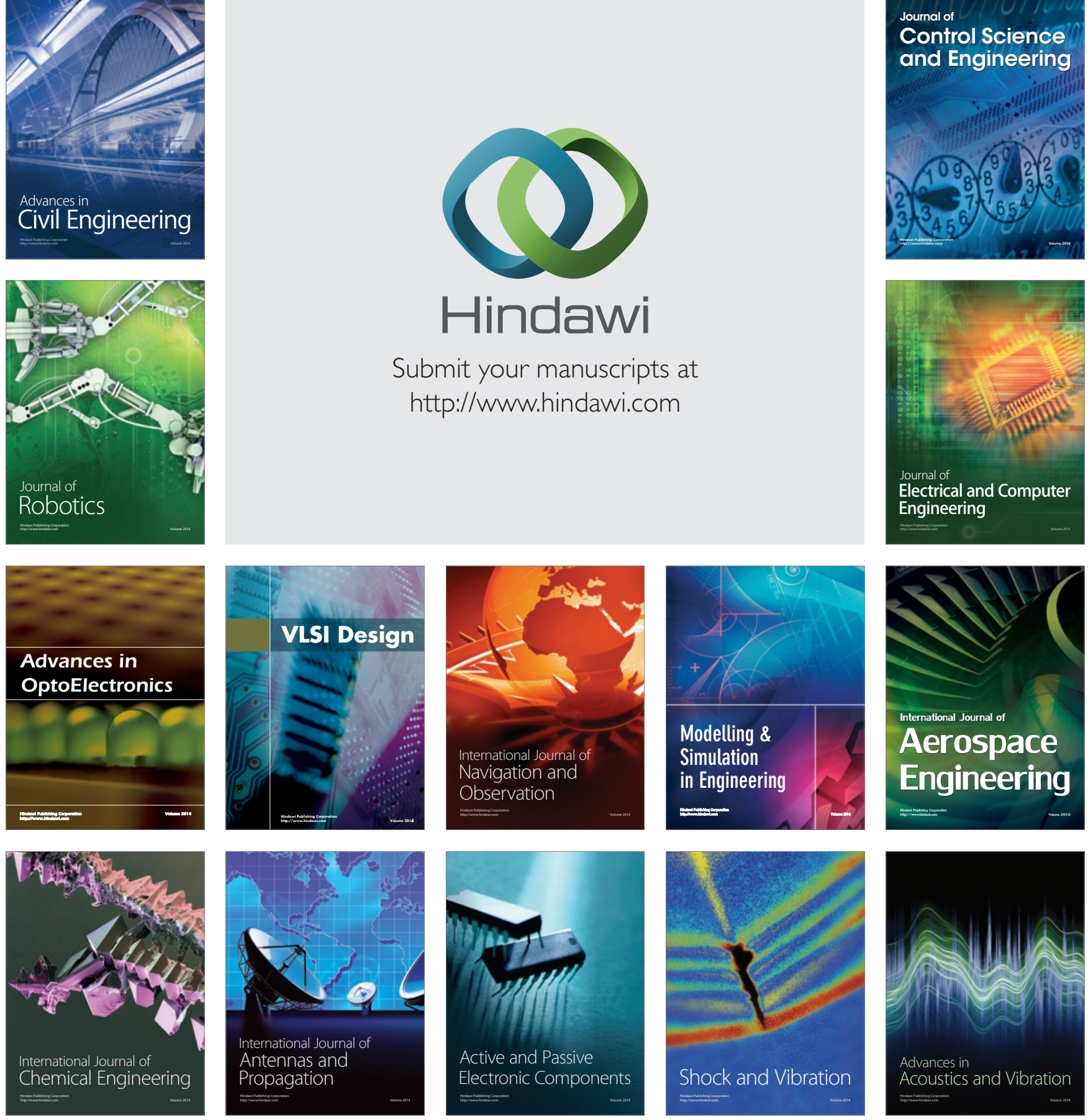